\title{
Towards a global understanding of vegetation-climate dynamics at multiple time scales
}

Running Title: Multi-scale vegetation-climate dynamics

Nora Linscheid, Lina M. Estupinan-Suarez, Alexander Brenning, Nuno Carvalhais, Felix Creme, Fabian Gans, Anja Rammig, Markus Reichstein, Carlos A. Sierra, Miguel D. Mahecha 
Supplementary Figures 

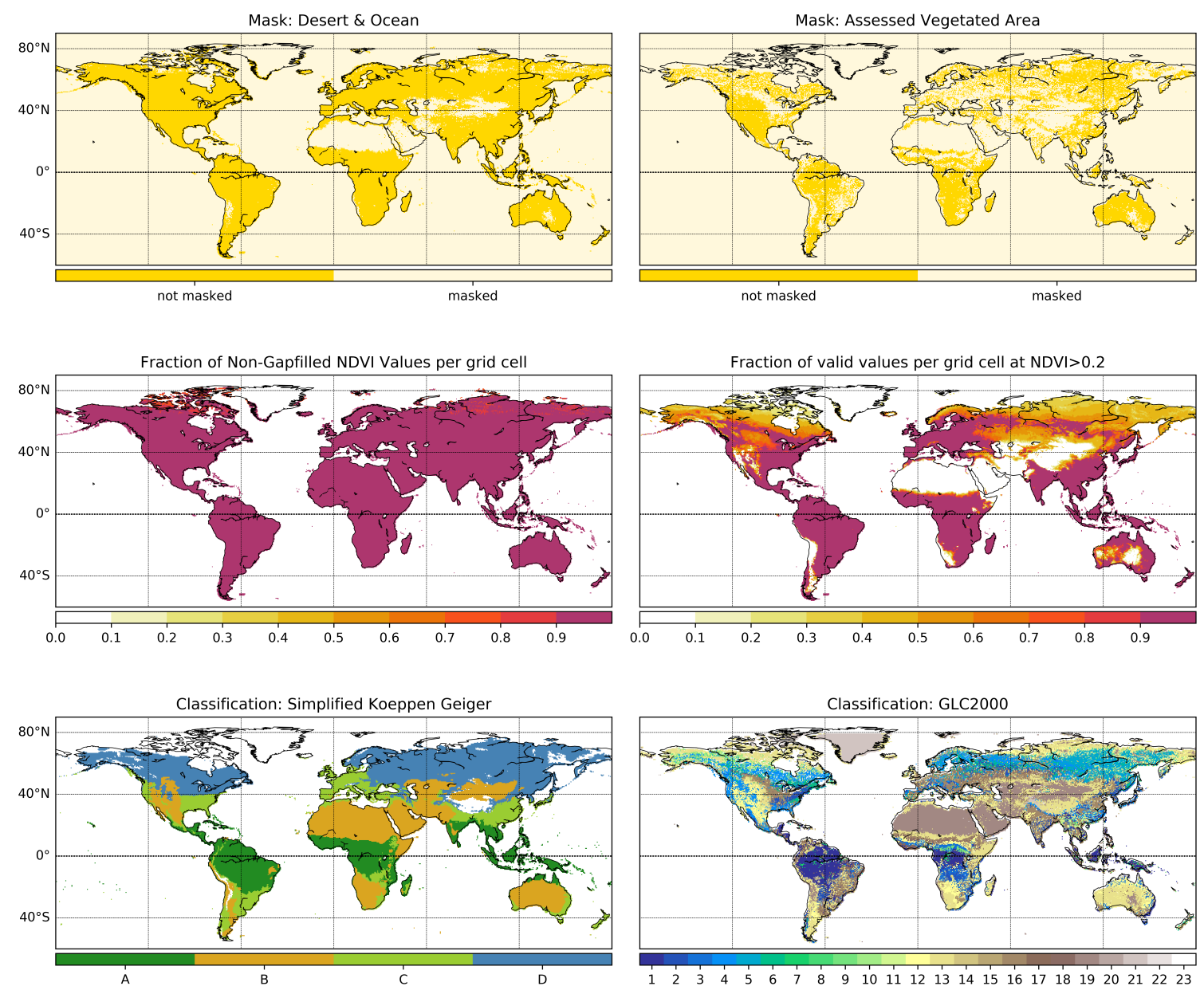

Figure S1: Masks and Classification schemes used in the analyses. a. Mask for deserts and oceans, b. Mask for natural vegetated area based on GLC2000, c. Fraction of non-gapfilled NDVI values per grid cell based on GIMMS NDVI, d. Fraction of valid values per grid cell after filtering for NDVI > 0.2, e. Simplified Köppen-Geiger Classification, A: equatorial, B: arid, C: warm temperate, D: snow, f. Classification of land cover classes after Global Land Cover 2000 (GLC2000). Numbers from 1-23 represent: 1 - Tree Cover broadleaved evergreen, 2 - Tree Cover broadleaved deciduous closed, 3 - Tree Cover broadleaved deciduous open, 4 - Tree Cover needle leaved evergreen, 5 - Tree Cover needle leaved deciduous, 6 - Tree Cover mixed leaf type, 7 - Tree Cover regularly flooded fresh water, 8 - Tree Cover regularly flooded saline water, 9 - Mosaic: Tree Cover and other natural vegetation, 10 - Tree Cover burnt, 11 - Shrub Cover closed open evergreen, 12 - Shrub Cover closed open deciduous, 13 - Herbaceous Cover closed open, 14 - Sparse herbaceous or sparse shrub cover, 15 - Regularly flooded shrub and or herbaceous cover, 16 - Cultivated and managed areas, 17 - Mosaic: Cropland Tree Cover Other natural vegetation, 18 - Mosaic: Cropland Shrub and or grass cover, $19-$ Bare Areas, 20 - Water Bodies, 21 - Snow and Ice, 22 - Artificial surfaces and associated areas, 23 no data. 

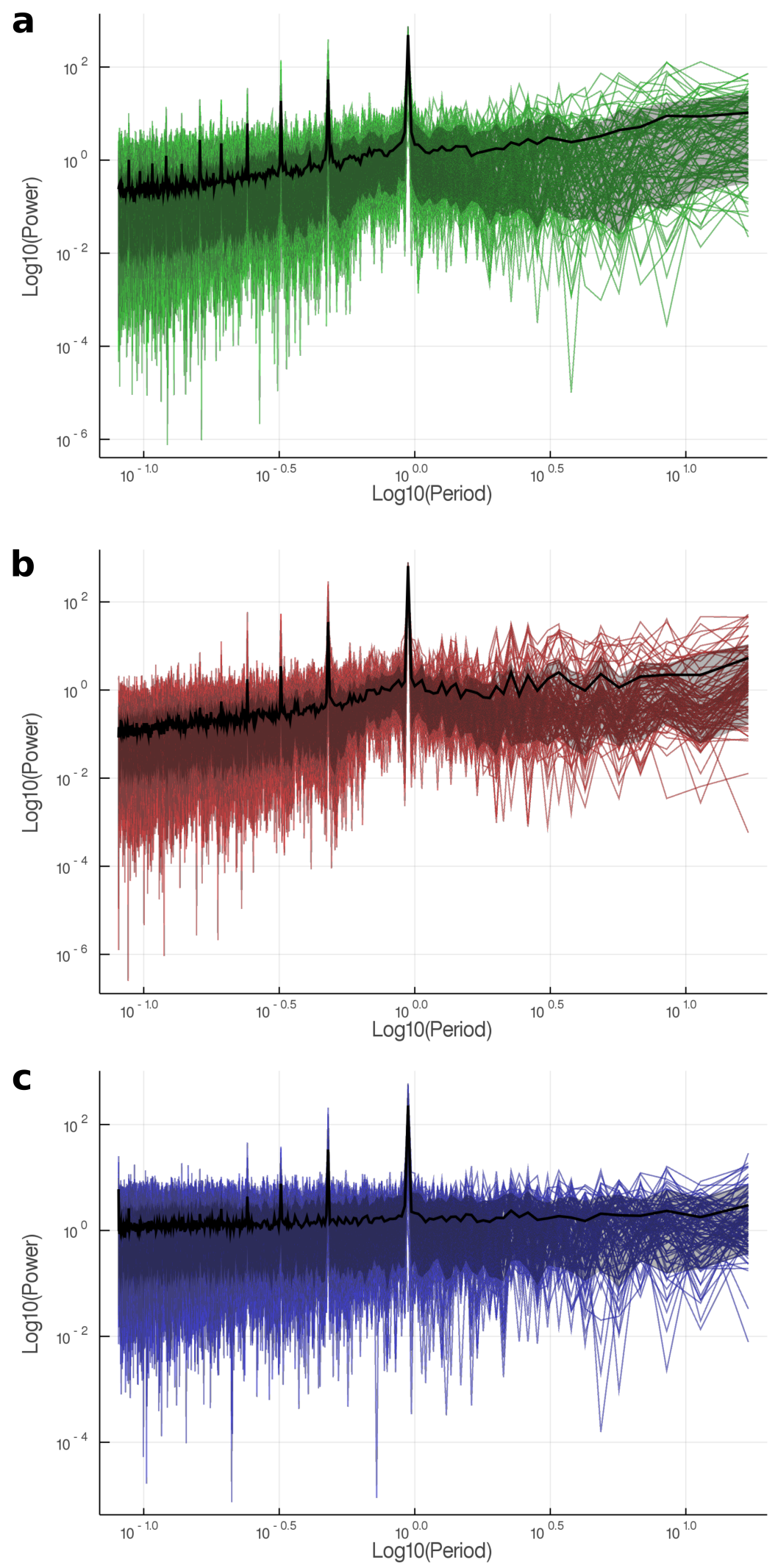

Figure S2: Representative power spectra of Fourier decomposed NDVI (a), air temperature (b) and precipitation (c) time series. Mean and 10th-90th percentile of power spectra are plotted as black line (mean) and band (percentiles), overlaid by 10000 sample spectra. Shortest signal periods (fastest frequencies) are plotted on the left side of the $\mathrm{x}$-axis, longest periods on the right side of the $\mathrm{x}$-axis. The annual period is located at $10^{0}$. 

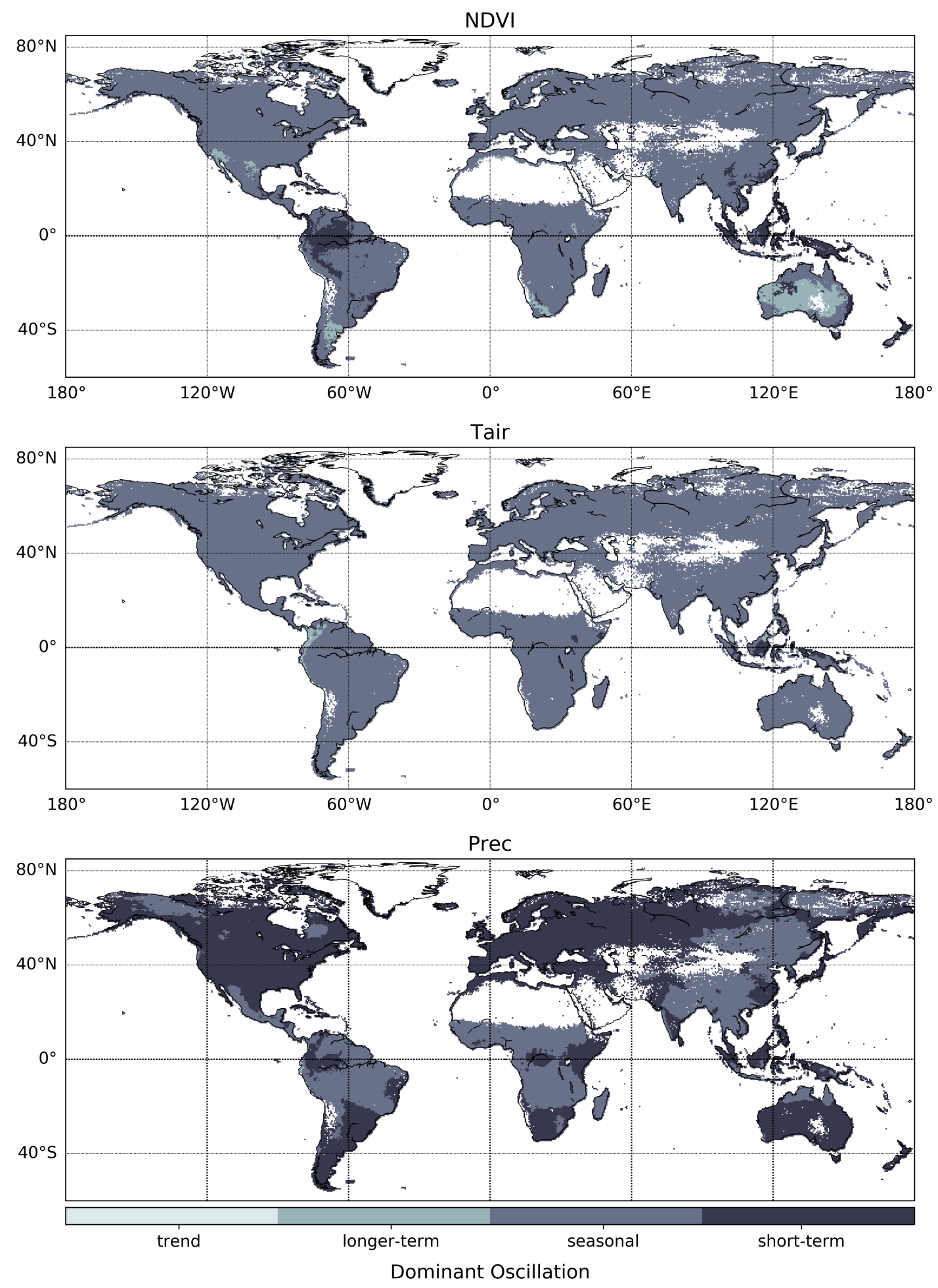

Figure S3: Dominant Oscillation of NDVI, air temperature $\left(\mathbf{T}_{\text {air }}\right)$ and precipitation (Prec) per grid cell. Dominant scale of variability was determined from normalized, detrended and decomposed time series as the time scale containing highest relative variance (cf. Fig. 1). 
a
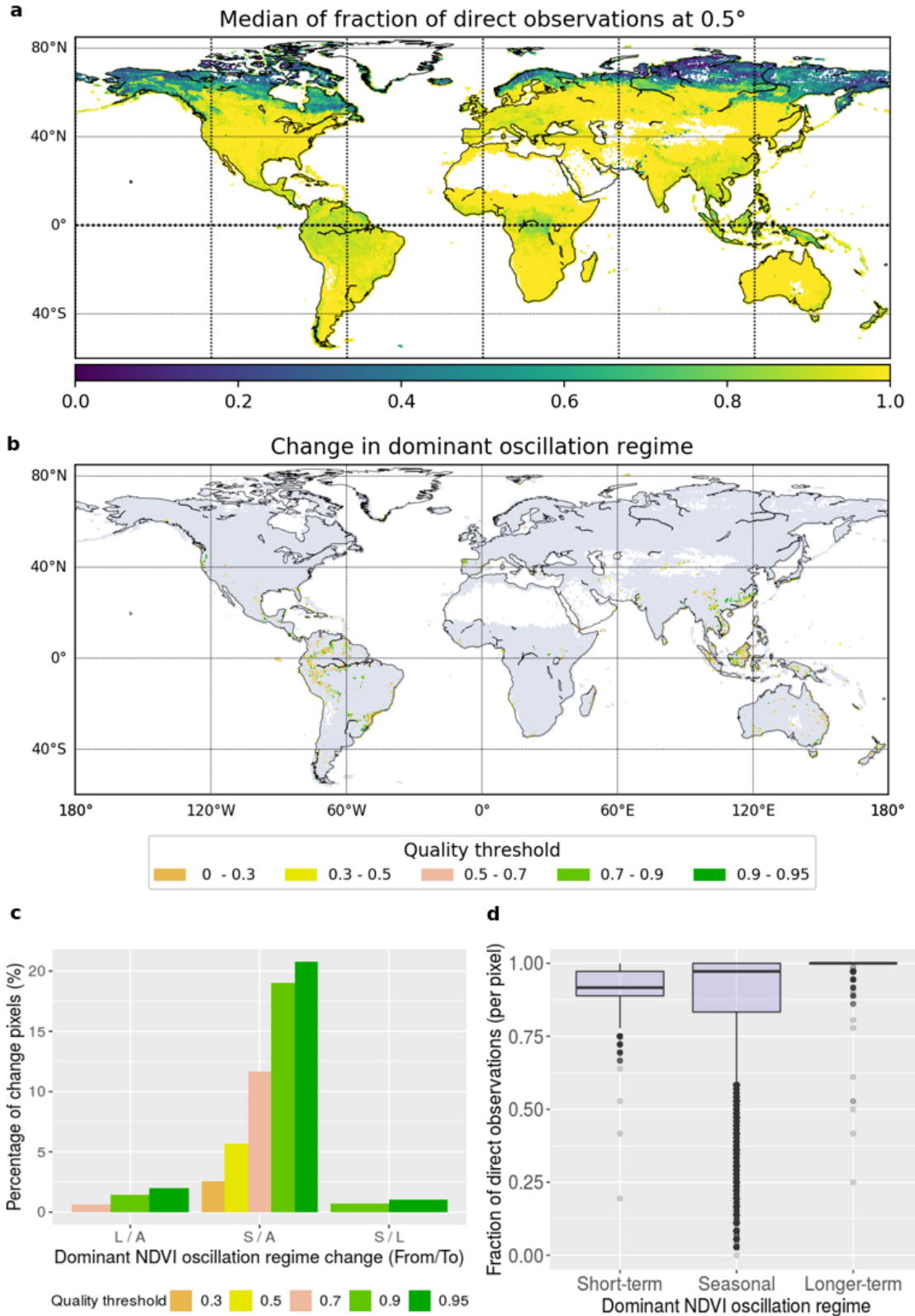

Figure S4: Assessment of NDVI GIMMS quality flags; direct observations and effect of retrieval values. a. Median of fraction of direct observations at $0.5^{\circ}$ per grid cell calculated overall time period (1982-2015). Fraction of direct observations ranges from 0 to 1 , and corresponds to the number of pixels with direct observation after data aggregation (from $0.083^{\circ}$ to $0.5^{\circ}$ ). Quality flag 1 is obtained when all aggregated pixels are direct observations, 0 if none are direct observations, b. Pixels that change NDVI dominant oscillation class when $0.3,0.5,0.7,0.9$, and 0.95 quality threshold is applied (quality is defined as the fraction of pixels originating from direct observations after aggregation), c. Percentage of pixels with change per dominant oscillation class. S: Short-term, A: Seasonal, L: Longer-term, T: Trend, in order from / to. Categories with change $<0.05 \%$ are omitted. d. Median fraction originating from direct observation per pixel shown as box plot per oscillation regime. Lowest percentage of direct observation is found in seasonal NDVI regimes. 

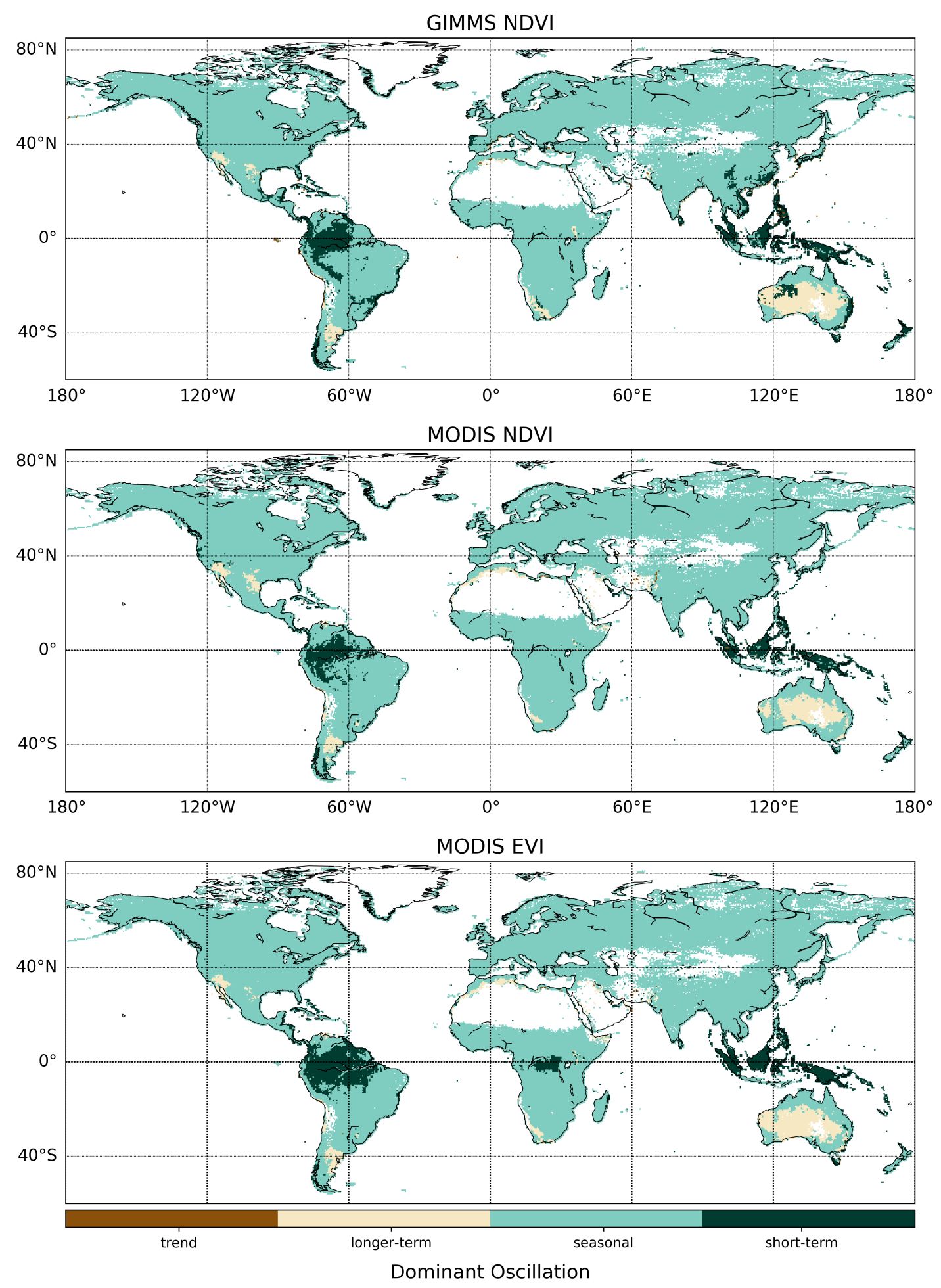

Figure S5: Comparison of dominant oscillation classification between vegetation indices. Dominant scale of variability for GIMMS NDVI from 1982 to 2015 (top), MODIS NDVI from 2001 to 2015 (center), and EVI MODIS from 2001 to 2015 (bottom). Dominant scale of variability was determined per pixel from normalized, detrended and Fourier-decomposed time series as the time scale containing highest relative variance. 

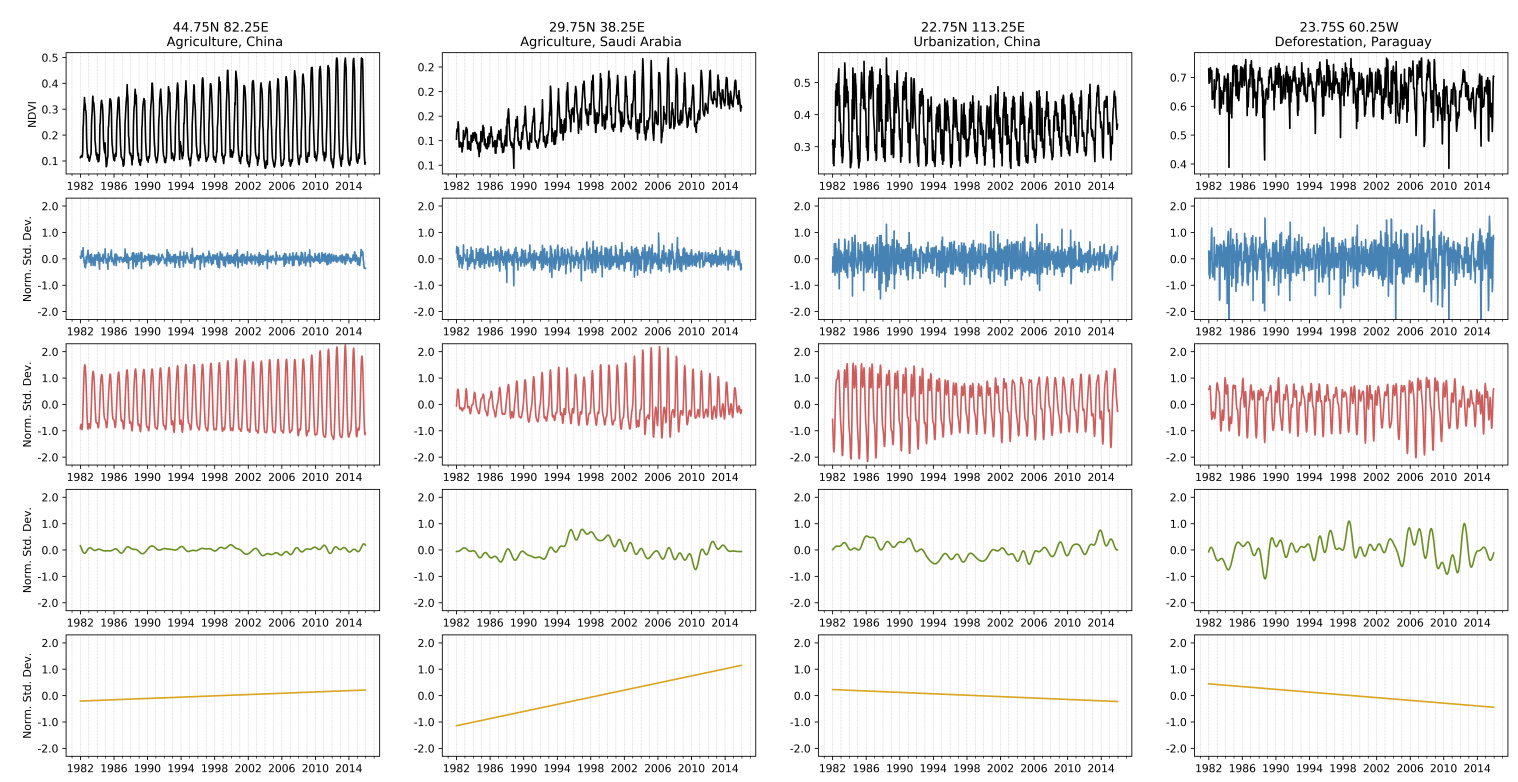

Figure S6: Assessment of the effect of land cover change over time on decomposition results of NDVI time series Four pixels with $>25 \%$ change in vegetation type according to Song et al. (2018) are displayed (columns), representing from left to right: (i) short vegetation gain, (ii) bare ground loss, (iii) bare ground gain, and (iv) tree loss. Rows from top to bottom: integrated NDVI signal (black), short-term oscillation (blue), seasonal oscillation (red), longer-term oscillation (green), and trend (yellow). Time series were normalized and detrended before Fourier decomposition. 

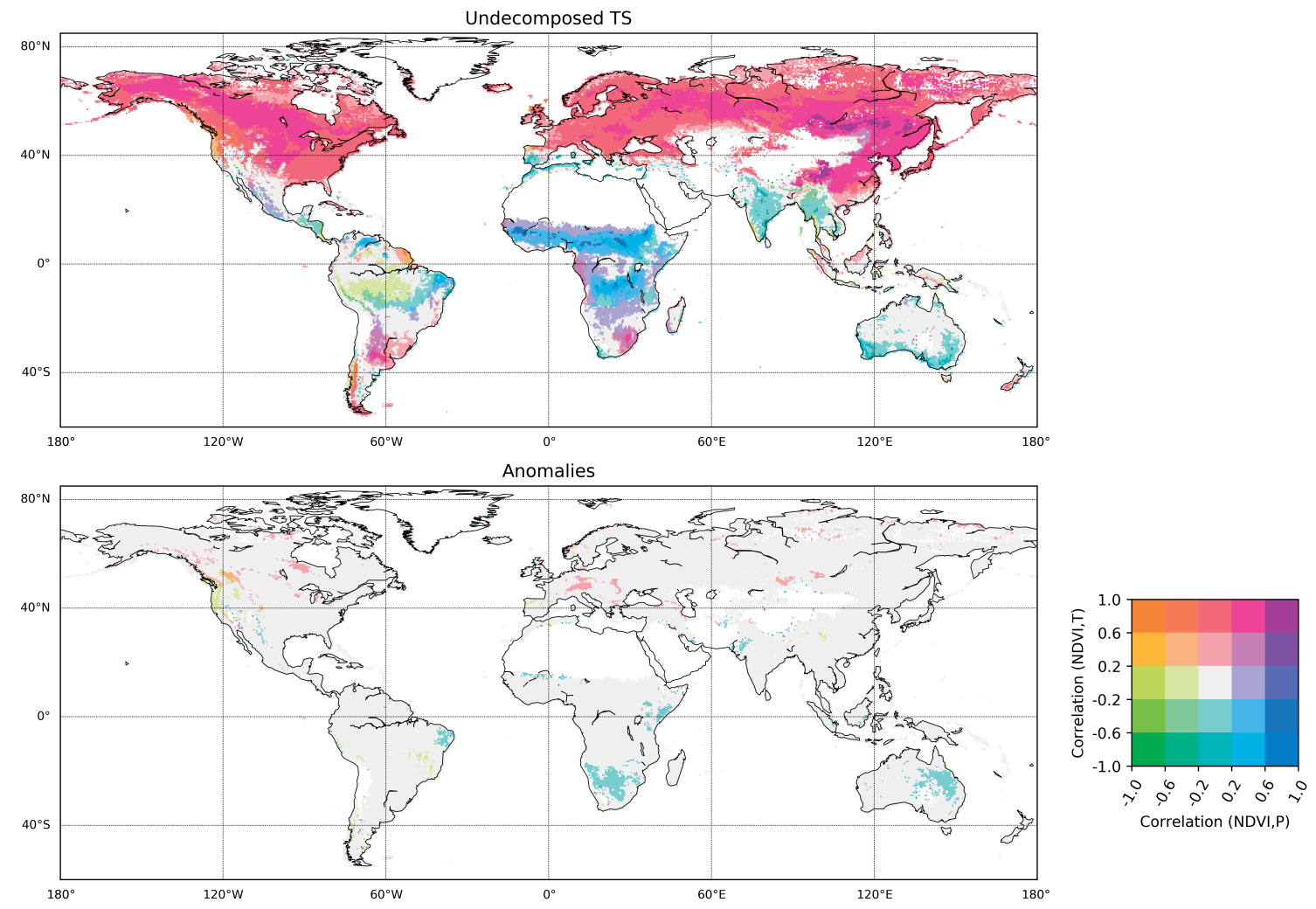

Figure S7: Bicolor map of undecomposed time series (top) and detrended, deseasonalized anomalies (bottom). Pearson correlation of NDVI with precipitation (Prec, legend $\mathrm{x}$ axis) and air temperature ( $\mathrm{T}_{\text {air }}$, legend y axis) is shown at each grid cell. NDVI was lagged one time step (15 days) behind precipitation to allow response time, $T_{\text {air }}$ was correlated instantaneously. Color scale represents both correlations, binned into quantiles (e. g. purple - high positive correlation of NDVI with both $\mathrm{T}_{a i r}$ and Prec, green - high negative correlation of NDVI with both $\mathrm{T}_{\text {air }}$ and Prec). Data points where NDVI $<0.2$ were excluded to avoid influence of inactive vegetation or non-vegetated time points. 

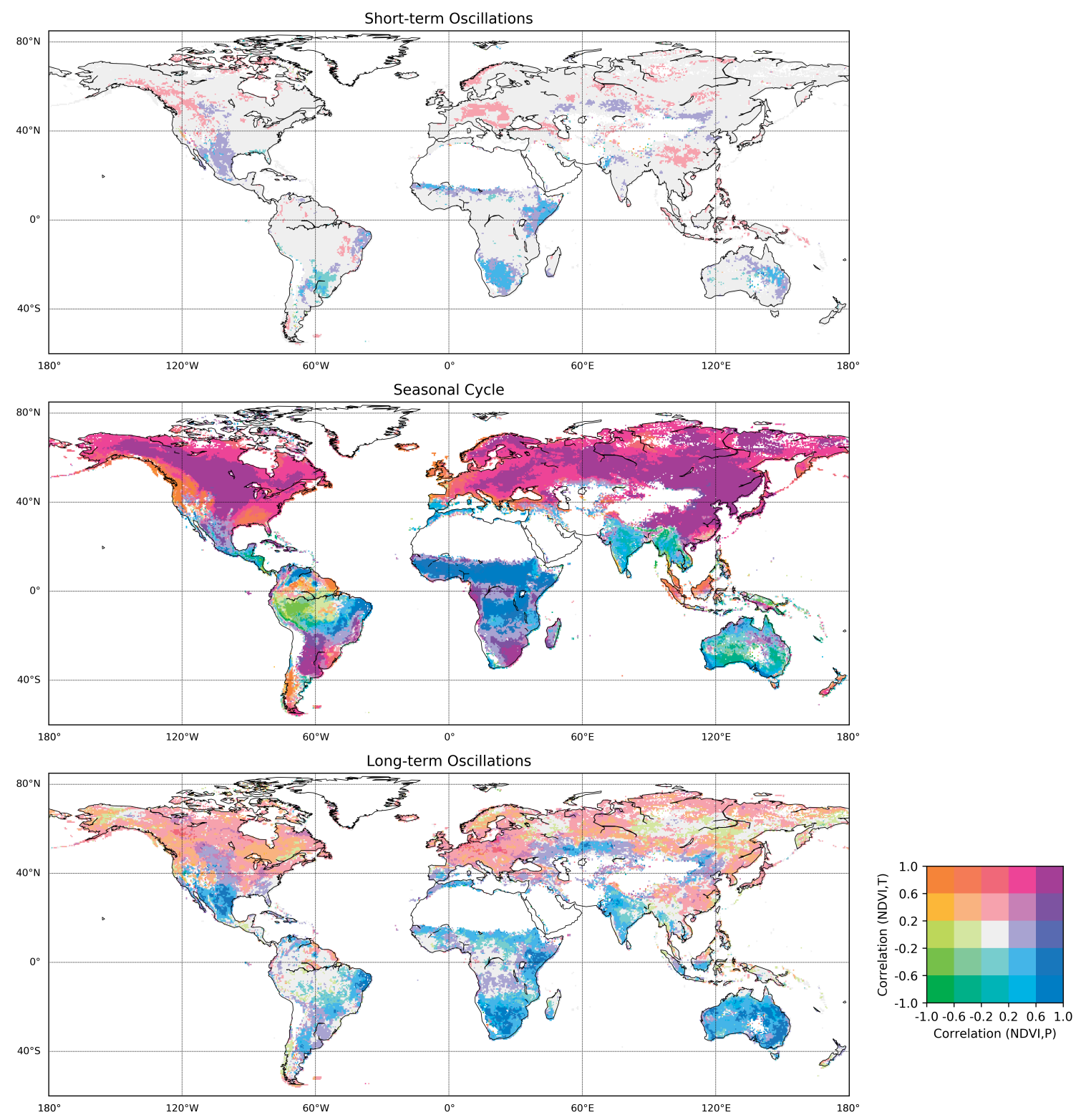

Figure S8: Bicolor map of Spearman correlations between NDVI, air temperature $\left(\mathbf{T}_{\text {air }}\right)$ and precipitation (Prec). Correlation of NDVI with $\mathrm{T}_{\text {air }}$ (legend y axis) and NDVI with Prec (legend $\mathrm{x}$ axis) were calculated between decomposed signals at each grid cell for each time scale (rows). NDVI was lagged one time step (15 days) behind precipitation to allow response time, $\mathrm{T}_{\text {air }}$ was correlated instantaneously. Color scale represents both correlations, binned into quantiles (e. g. purple - high positive correlation of NDVI with both $\mathrm{T}_{a i r}$ and Prec, green - high negative correlation of NDVI with both $\mathrm{T}_{\text {air }}$ and Prec). Data points where NDVI $<0.2$ were excluded to avoid influence of inactive vegetation or non-vegetated time points. The semi-annual cycle is included in the seasonal band. 

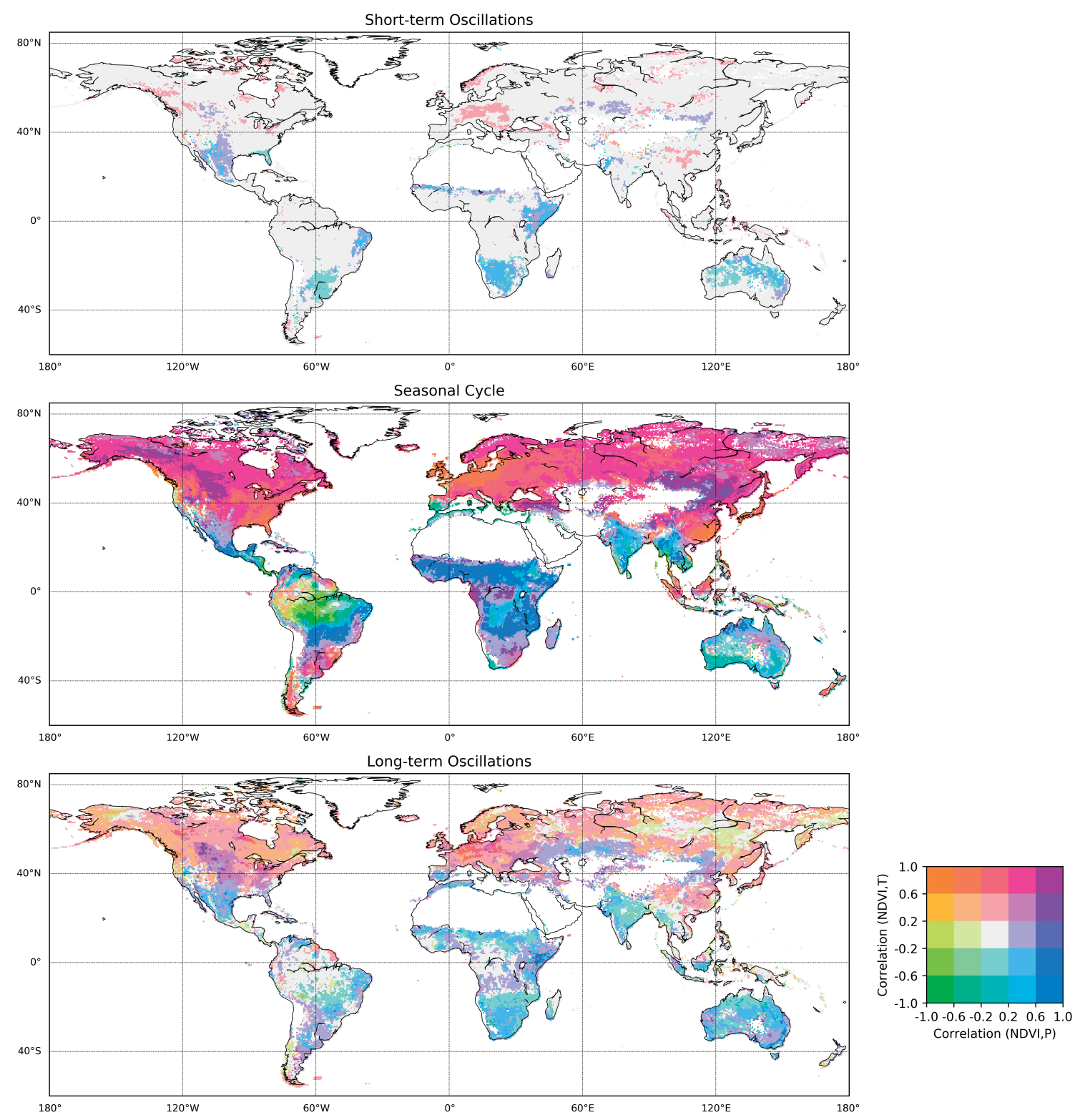

Figure S9: Bicolor map of Partial correlations between NDVI, air temperature $\left(\mathbf{T}_{\text {air }}\right)$ and precipitation (Prec). Correlation of NDVI with $\mathrm{T}_{\text {air }}$ (legend y axis) and NDVI with Prec (legend $\mathrm{x}$ axis) were calculated between decomposed signals at each grid cell for each time scale (rows). NDVI was lagged one time step (15 days) behind precipitation to allow response time, $\mathrm{T}_{\text {air }}$ was correlated instantaneously. Color scale represents both correlations binned into quantiles (e. g. purple - high positive correlation of NDVI with both $\mathrm{T}_{a i r}$ and Prec, green - high negative correlation of NDVI with both $\mathrm{T}_{a i r}$ and Prec). Data points where NDVI $<0.2$ were excluded to avoid influence of inactive vegetation or non-vegetated time points. The semi-annual cycle is included in the seasonal band. 


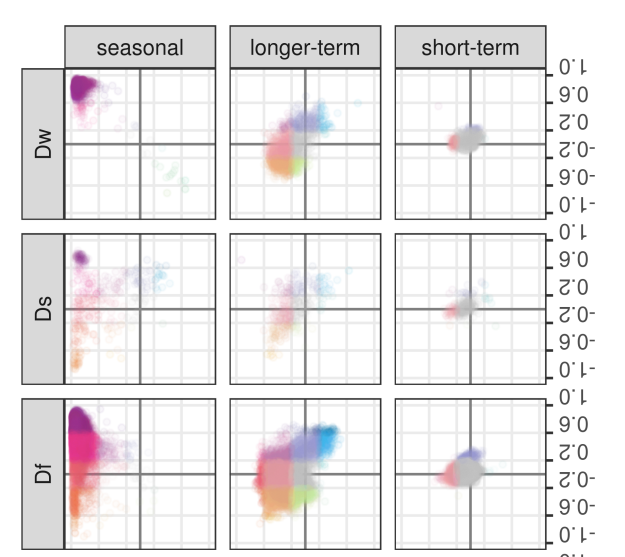

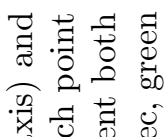

तु

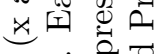

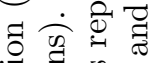

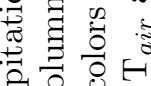
웡

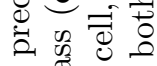
군 3 o 50

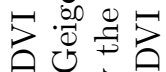
完宣是 पे

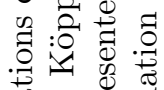
蛋 का $\dot{0} \dot{0}=$ $\dot{0} 00$ 过露 \&

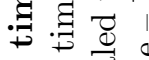
点 บ्ञ ๘ 웡

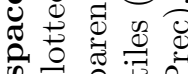
की 2 要

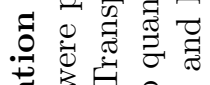
首

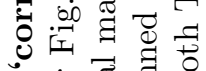

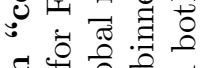
$\therefore 4 \frac{1}{0} \frac{0}{0}$ of 000

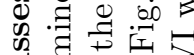

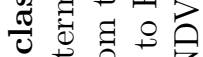

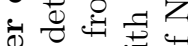

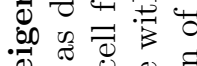

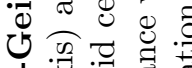

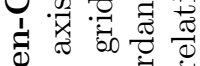

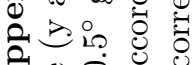
:0 $\checkmark \exists \Xi$.

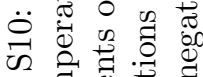

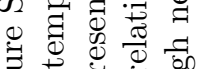

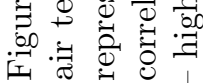




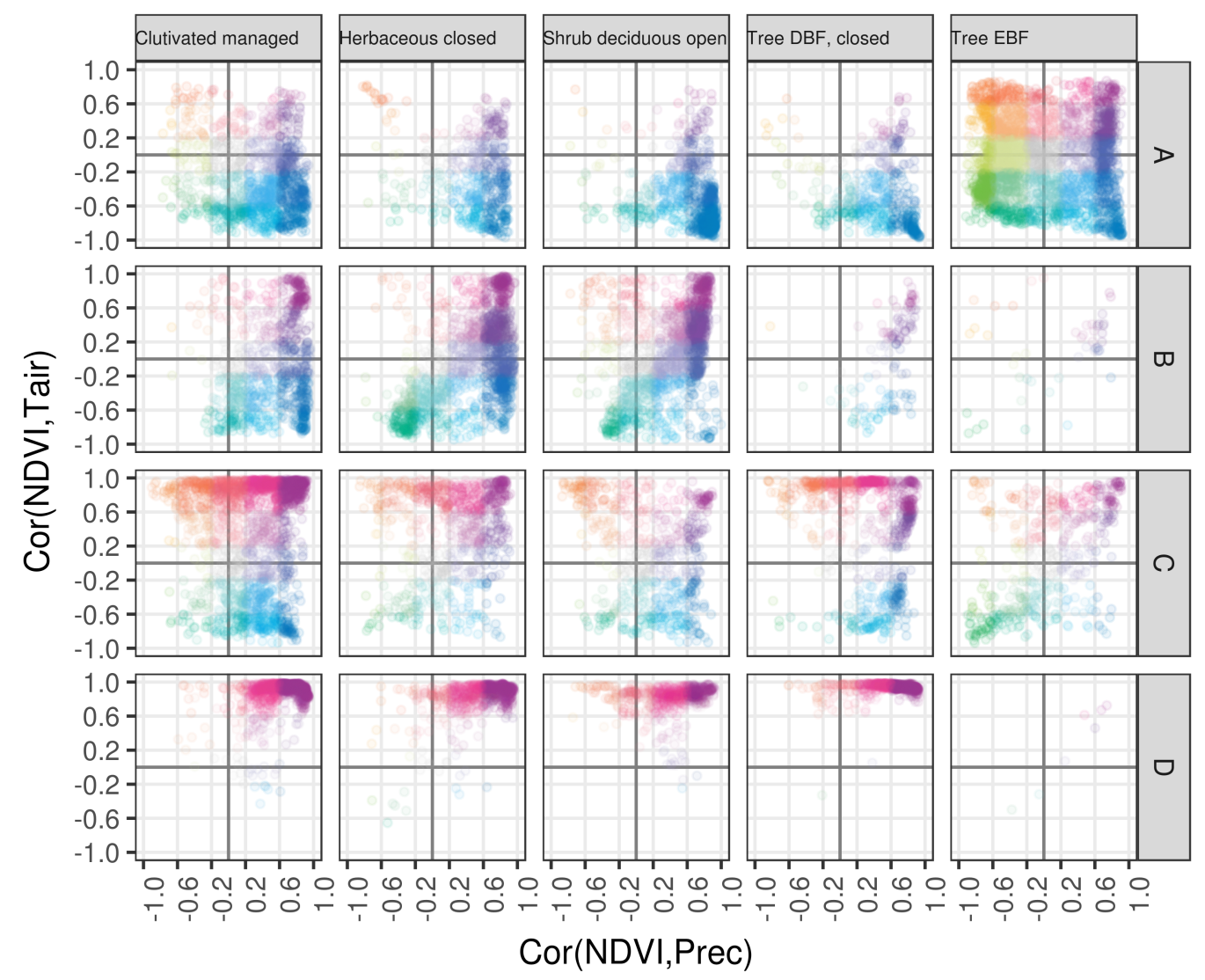

Figure S11: Land cover classes in "correlation space" across Köppen-Geiger classes for seasonal scale. Correlations of NDVI with precipitation ( $\mathrm{x}$ axis) and air temperature (y axis) as determined for Fig. 3 were plotted for major land cover classes (GLC2000, columns) across KöppenGeiger classes (rows). Each point represents one $0.5^{\circ}$ grid cell from the global map. Transparency was scaled with the area represented by the grid cell, colors represent both correlations in accordance with to Fig. 3 binned into quantiles (e. g. purple - high positive correlation of NDVI with both $\mathrm{T}_{\text {air }}$ and Prec, green - high negative correlation of NDVI with both $\mathrm{T}_{\text {air }}$ and Prec). A - equatorial, $\mathrm{B}$ arid, $\mathrm{C}$ - warm temperate, $\mathrm{D}$ - snow) 


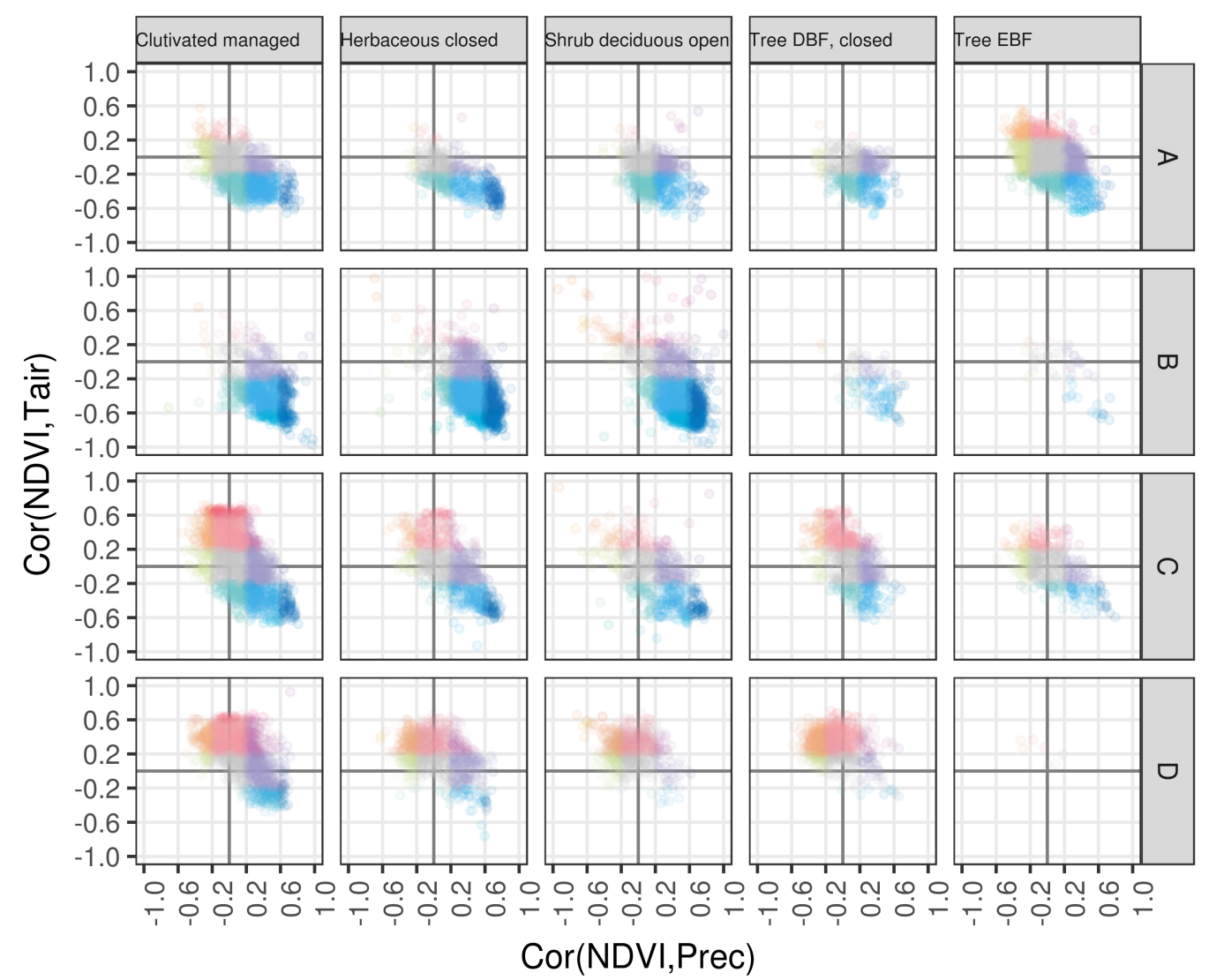

Figure S12: Land cover classes in "correlation space" across Köppen-Geiger classes for longer-term scale. Correlations of NDVI with precipitation (x axis) and air temperature (y axis) as determined for Fig. 3 were plotted for major land cover classes (GLC2000, columns) across KöppenGeiger classes (rows). Each point represents one $0.5^{\circ}$ grid cell from the global map. Transparency was scaled with the area represented by the grid cell, colors represent both correlations in accordance with to Fig. 3 binned into quantiles (e. g. purple - high positive correlation of NDVI with both $\mathrm{T}_{\text {air }}$ and Prec, green - high negative correlation of NDVI with both $\mathrm{T}_{\text {air }}$ and Prec). A - equatorial, $\mathrm{B}-$ arid, $\mathrm{C}$ - warm temperate, D - snow) 

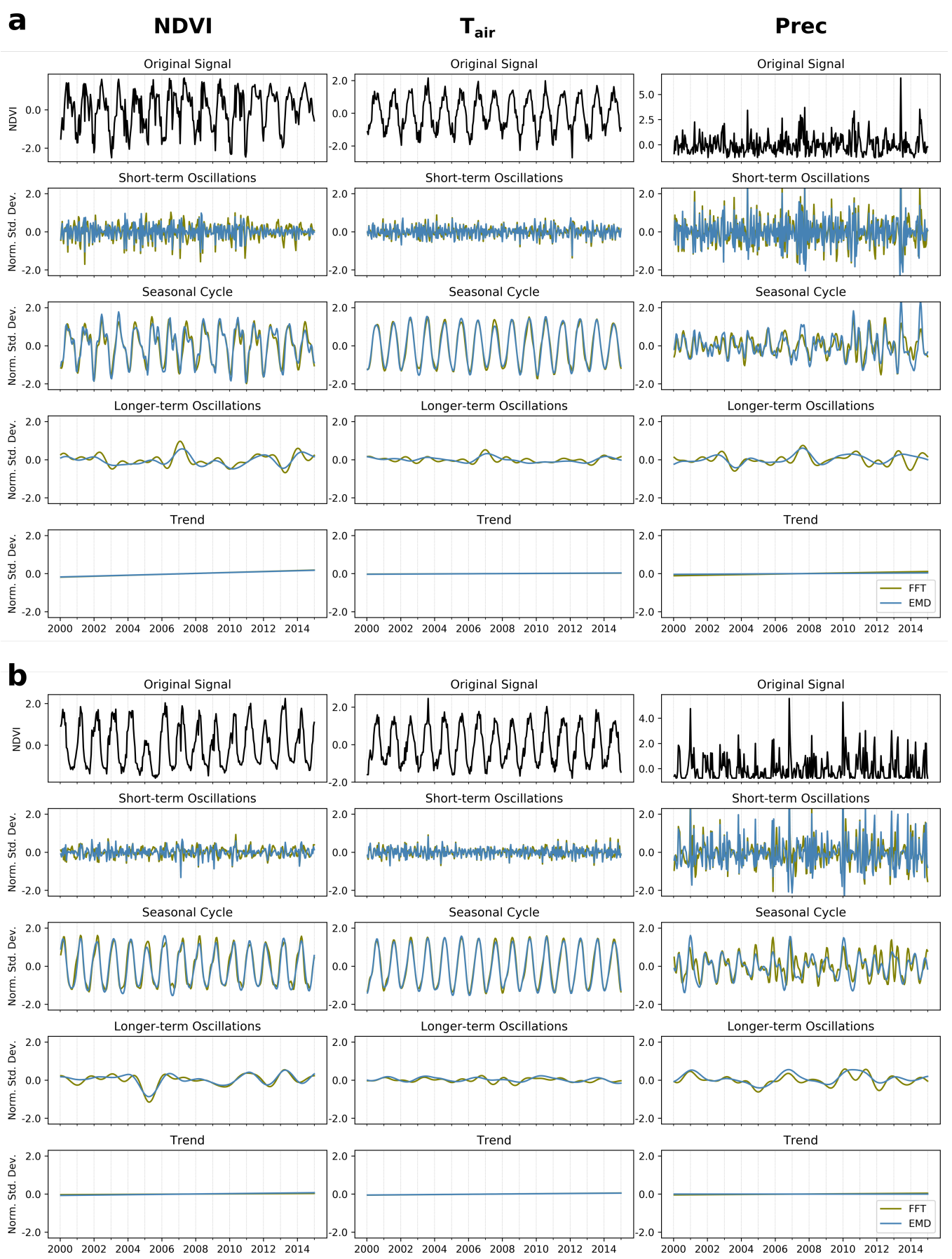

Figure S13: Temporal comparison of Fourier transformation (FFT) and Empirical Mode Decomposition (EMD). Time series examples for a. Germany (lon. $11^{\circ}$, lat. $51^{\circ}$ ), and b. southern Portugal (lon. $-8^{\circ}$, lat. $38^{\circ}$ ) of decomposed time series of NDVI, air temperature $\left(\mathrm{T}_{\text {air }}\right)$ and precipitation (Prec) from 2000-2014. FFT signals are colored green, EMD signals are colored blue. 

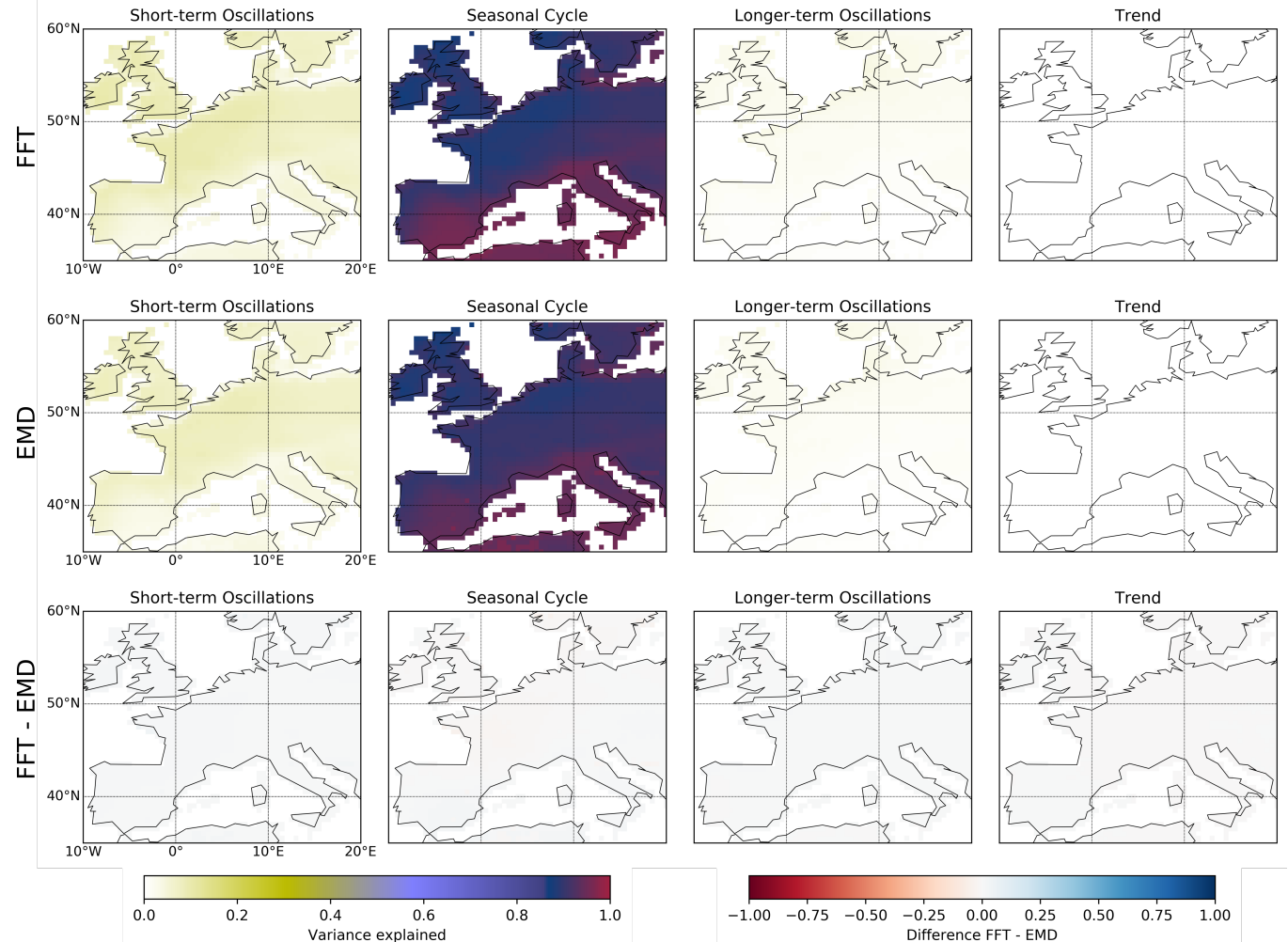

Figure S14: Spatial comparison of Fourier transformation (FFT) and Empirical Mode Decomposition (EMD). Comparison of variance explained per pixel as determined for NDVI time series (2000-2014) by Fourier transformation (FFT, upper row) and empirical mode decomposition (EMD), as well as their difference (lower row) over Europe. 

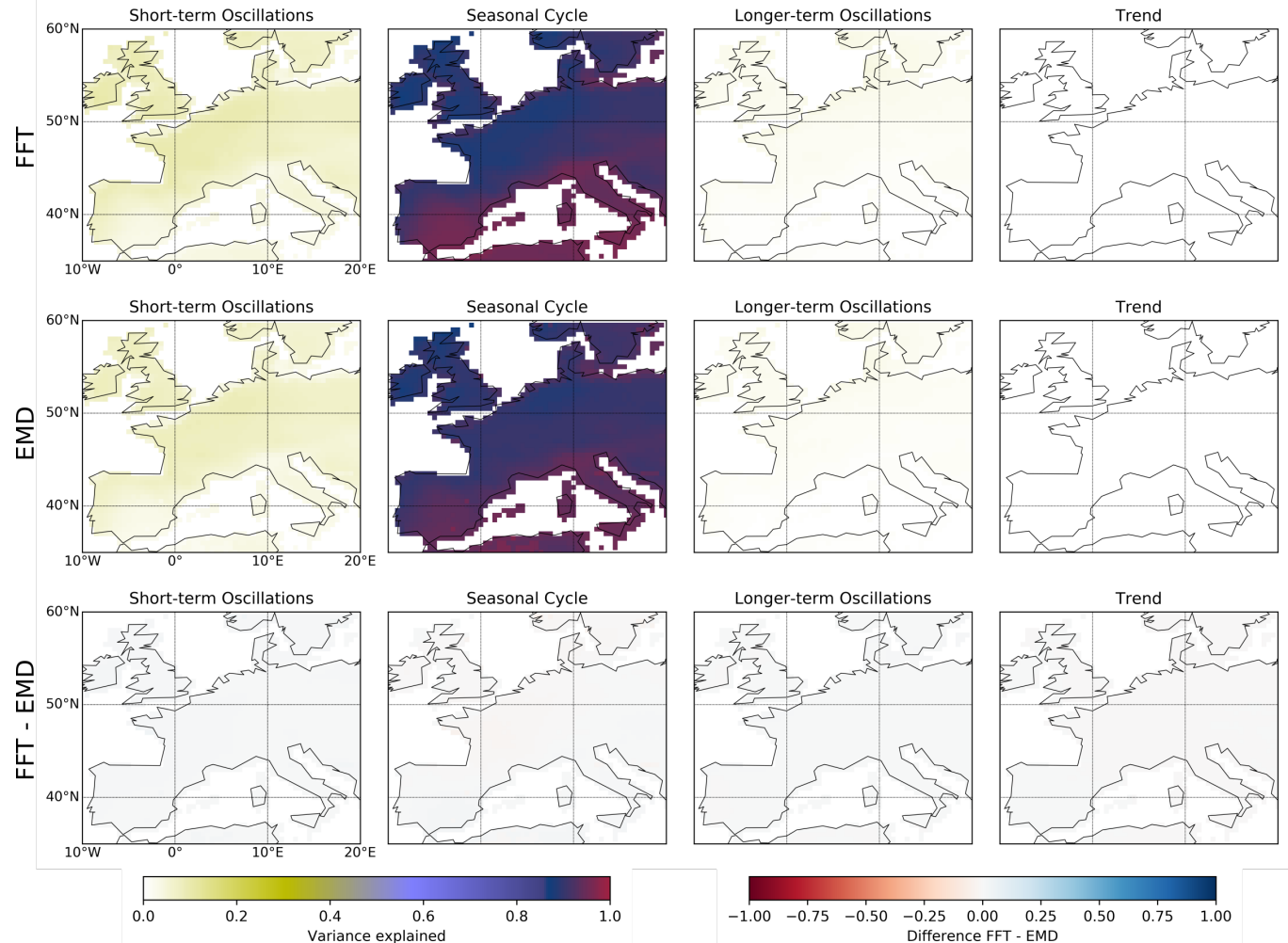

Figure S15: Spatial comparison of Fourier transformation (FFT) and Empirical Mode Decomposition (EMD). Comparison of variance explained per pixel as determined for air temperature time series (2000-2014) by Fourier transformation (FFT, upper row) and empirical mode decomposition (EMD), as well as their difference (lower row) over Europe. 

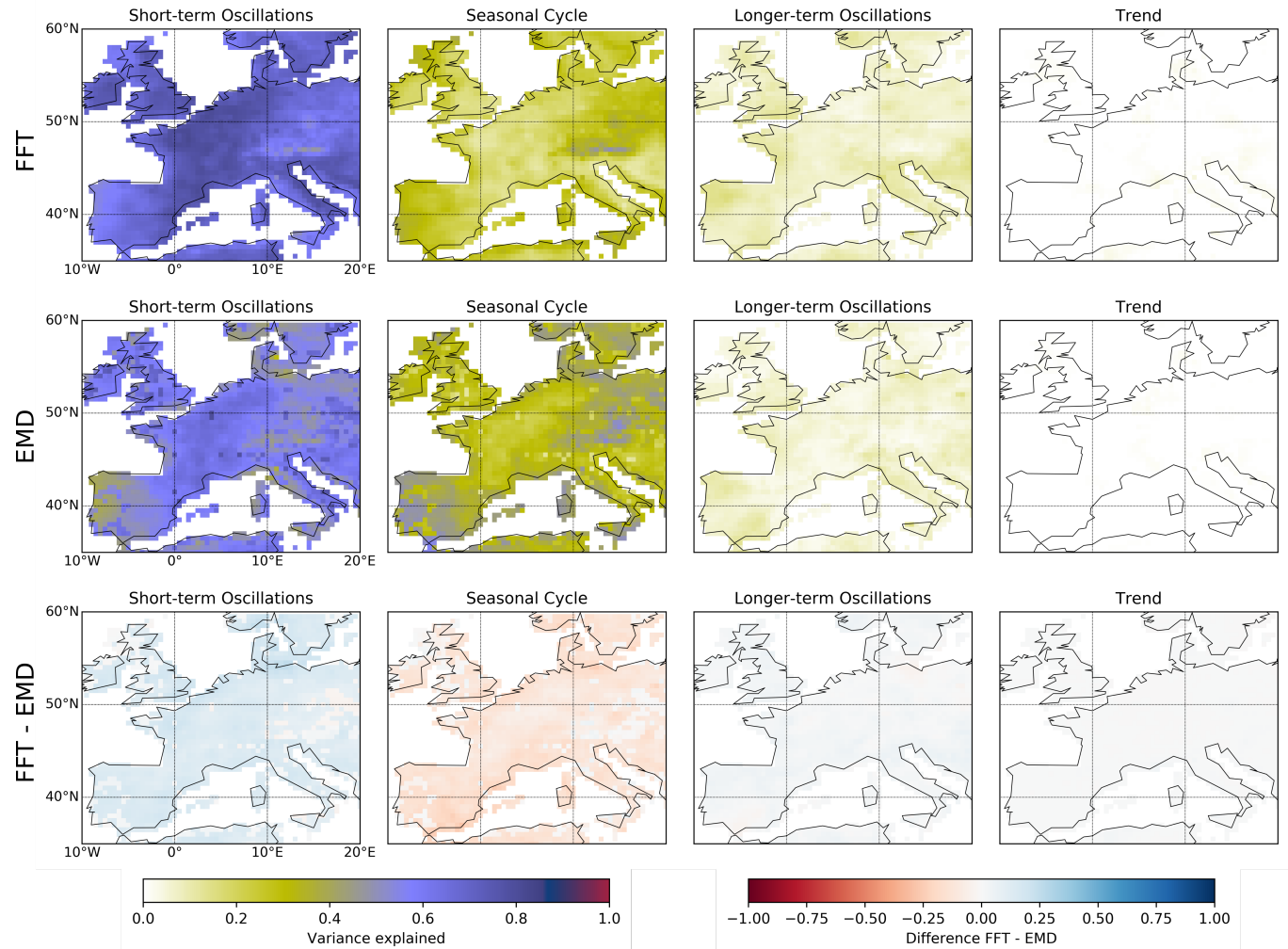

Figure S16: Spatial comparison of Fourier transformation (FFT) and Empirical Mode Decomposition (EMD). Comparison of variance explained per pixel as determined for precipitation time series (2000-2014) by Fourier transformation (FFT, upper row) and empirical mode decomposition (EMD), as well as their difference (lower row) over Europe. 


\section{Supplementary Tables}

Table S1: Selected and excluded classes from GLC 2000.

\begin{tabular}{ll}
\hline \multicolumn{2}{c}{ Selected land cover classes } \\
\hline Herbaceous cover closed open & Tree cover broadleaved deciduous open \\
Mosaic: Tree cover other natural vegetation & Tree cover broadleaved evergreen \\
Regularly flooded shrub and or herbaceous cover & Tree cover mixed leaf type \\
Shrub cover closed open deciduous & Tree cover needle leaved deciduous \\
Shrub cover closed open evergreen & Tree cover needle leaved evergreen \\
Sparse herbaceous or sparse shrub cover & Tree cover regularly flooded fresh water \\
Tree cover broadleaved deciduous closed & Tree cover regularly flooded saline water \\
\hline \multicolumn{2}{c}{ Excluded land cover classes } \\
\hline \multirow{2}{*}{ Artificial surfaces and associated areas } & Mosaic: Cropland / Tree cover / \\
Bare areas & Other natural vegetation \\
Cultivated and managed areas & Snow and ice (natural \& artificial) \\
Mosaic: Cropland / Shrub or grass cover & Tree cover burnt \\
\hline
\end{tabular}


Table S2: Global weighted mean of decomposed oscillations and three latitudinal bands (i) extratropics northern hemisphere (above $23.5^{\circ} \mathrm{N}$ ), (ii) tropics $\left(23.5^{\circ} \mathrm{N}\right.$ to $23.5^{\circ} \mathrm{S}$ ) and (iii) extratropics southern hemisphere (below $23.5^{\circ} \mathrm{S}$ ). The mean weights are based on pixel area.

\begin{tabular}{llllll}
\hline Variable & Region & $\begin{array}{l}\text { Short- } \\
\text { term }\end{array}$ & Seasonal & $\begin{array}{l}\text { Longer- } \\
\text { term }\end{array}$ & Trend \\
\hline NDVI & Global & 0.18 & 0.71 & 0.09 & 0.02 \\
\hline NDVI & Above 23.5 N & 0.1 & 0.84 & 0.05 & 0.01 \\
NDVI & Tropics & 0.27 & 0.59 & 0.11 & 0.02 \\
NDVI & Below 23.5 S & 0.25 & 0.46 & 0.25 & 0.03 \\
\hline Tair & Global & 0.11 & 0.83 & 0.04 & 0.01 \\
\hline Tair & Above 23.5 N & 0.05 & 0.94 & 0.01 & 0 \\
Tair & Tropics & 0.21 & 0.68 & 0.09 & 0.02 \\
Tair & Below 23.5 S & 0.08 & 0.9 & 0.02 & 0 \\
\hline Prec & Global & 0.52 & 0.41 & 0.06 & 0 \\
\hline Prec & Above 23.5 N & 0.57 & 0.36 & 0.06 & 0 \\
Prec & Tropics & 0.42 & 0.51 & 0.06 & 0 \\
Prec & Below 23.5 S & 0.68 & 0.24 & 0.09 & 0 \\
\hline
\end{tabular}


Table S3: Summary statistics of total area assessed and percentage of dominant NDVI oscillations by Köppen-Geiger, vegetated land cover classes and dominant oscillations of climatic variables. A: Annual, L: Longer-term, S:Short-term, T: Trend. Values of $\mathrm{T}$ are solely presented for area calculations.

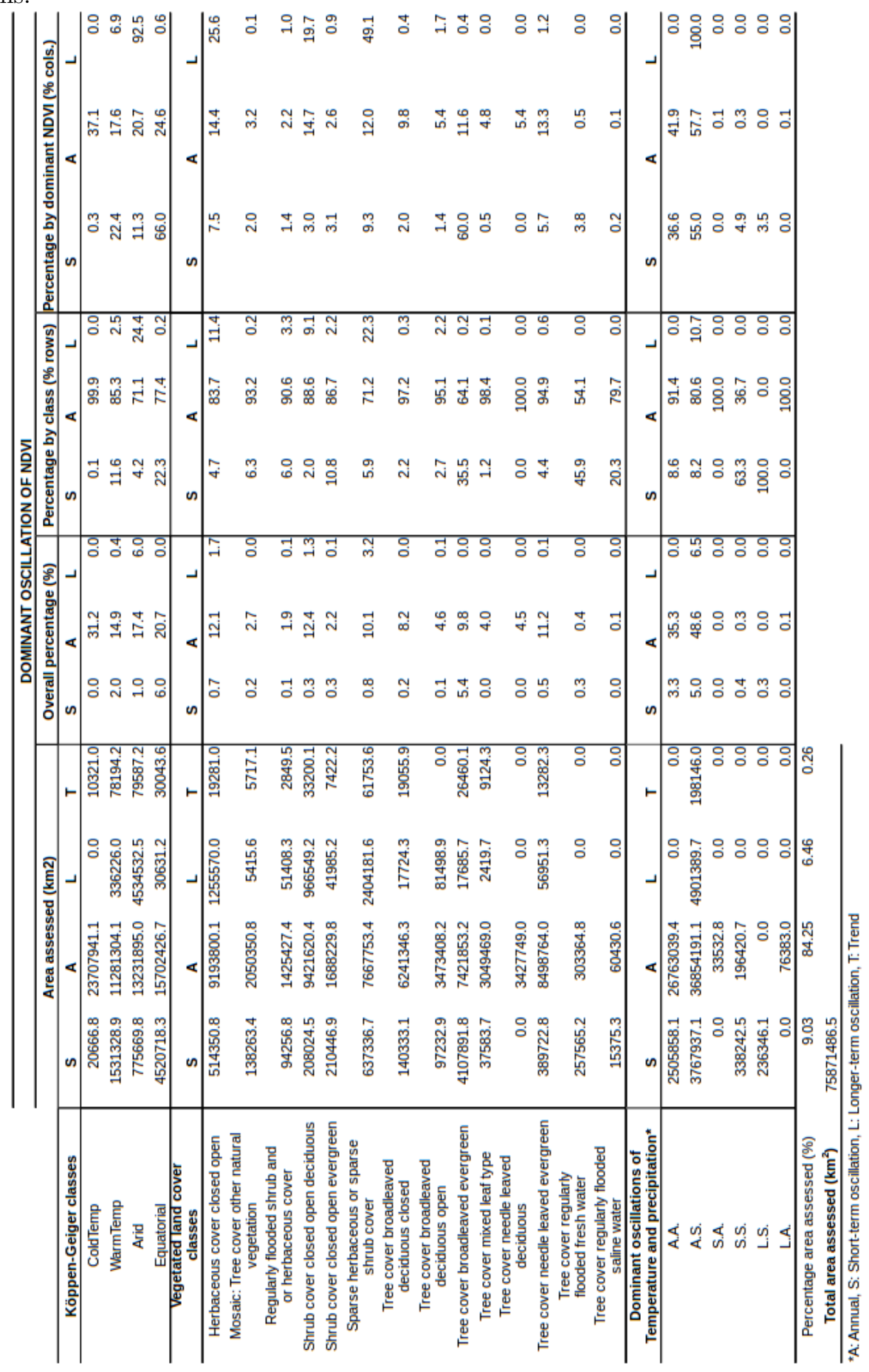




\section{References}

Song, X.-P., Hansen, M. C., Stehman, S. V., Potapov, P. V., Tyukavina, A., Vermote, E. F., \& Townshend, J. R. (2018, August). Global land change from 1982 to 2016. Nature, 560, 639-643. doi: $10.1038 /$ s41586-018-0411-9 